Article

\title{
A Potential Antineoplastic Peptide of Human Prostate Cancer Cells Derived from the Lesser Spotted Dogfish (Scyliorhinus canicula L.)
}

\author{
Adrien Bosseboeuf ${ }^{1}$, Amandine Baron ${ }^{2}$, Elise Duval ${ }^{2}$, Aude Gautier ${ }^{1}$, Pascal Sourdaine ${ }^{1, *}$ \\ and Pierrick Auvray ${ }^{2, *}$ \\ 1 Sciences Department, Normandy University, University of Caen Normandy (UNICAEN), Sorbonne \\ University, French National Museum of Natural History (MNHN), University of Antilles (UA), French \\ National Centre for Scientific Research (CNRS), French National Institute for Sustainable \\ Development (IRD), Biology of Aquatic Organisms and Ecosystems (BOREA) Research Unit, CS14032, 14032 \\ CAEN, CEDEX 5, France; ABosseboeuf@salud.unm.edu (A.B.); aude.gautier@unicaen.fr (A.G.) \\ 2 Group CELLIS PHARMA, Parc Technopolitain Atalante Saint Malo, 35400 Saint Malo, France; \\ a.baron@kelia-pharma.com (A.B.); e.duval@kelia-pharma.com (E.D.) \\ * Correspondence: pascal.sourdaine@unicaen.fr (P.S.); p.auvray@cellispharma.com (P.A.); \\ Tel.: +33231565687 (P.S.); +33299196970 (P.A.)
}

Received: 24 September 2019; Accepted: 14 October 2019; Published: 16 October 2019

\begin{abstract}
The purpose of the present paper is to investigate the mechanism of action of a pyroglutamate-modified peptide ( $\mathrm{pE}-\mathrm{K} 092 \mathrm{D}$ ) on in vitro growth inhibition of MDA-Pca- $2 \mathrm{~b}$ prostate cancer cells. This peptide was derived from a peptide previously isolated from the testis of the lesser spotted dogfish and identified as QLTPEALADEEEMNALAAR (K092D). The effect of the peptide on cell proliferation and cell death mechanisms was studied by flow cytometry. Cellular morphology and cytoskeleton integrity of peptide-treated cells were observed by immunofluorescence microscopy. Results showed the onset of peptide induced early cytoskeleton perturbation, inhibition of autophagy, inhibition of cell proliferation and, at the end, non-apoptotic cell death mechanisms (membrane destabilization and necrosis). All those mechanisms seem to contribute to MDA-Pca-2b growth inhibition by a main cytostatic fate.
\end{abstract}

Keywords: cancer; MDA-Pca-2b; antineoplastic; marine peptide; lesser spotted dogfish (Scyliorhinus canicula)

\section{Introduction}

Due to their large biodiversity, marine organisms are an interesting source of bioactive peptides exhibiting various biological characteristics, including anticancer properties [1-3]. Marine bioactive peptides exert different mechanisms of action on cancer cells such as plasma membrane disruption, cytoskeleton disorganization, oxidative regulation, inhibition of gene expression, cell-cycle arrest, apoptosis induction or inhibition of angiogenesis [4,5]. Among these bioactive peptides, or their derivatives, some have anti-prostate cancer properties [6]. As examples, peptides derived from Sepia ink such as the Sepia Ink Oligopeptide (SIO) and the Sepia Hydrolyzed Peptide (SHP) induced apoptosis on prostate cancer cell lines through downregulation of Bcl-2, upregulation of BAX and caspase-3 activation [7,8]. Further peptides derived from other marine mollusks have been recently reported as inducing apoptosis on prostate cancer cells $[9,10]$.

Among marine animals, chondrichthyans seem to be an interesting class where active molecules may be found as illustrated by squalamine, an aminosterol blocking tumor-associated or age-related macular degeneration (AMD)-associated angiogenesis and also exhibiting a broad-spectrum 
antimicrobial activity [11-14]. Few bioactive peptides have been characterized from chondrichthyans such as the SHRSF (shark liver Hepatocyte Regeneration Stimulatory Factor) and others with angiotensin I-converting enzyme (ACE) inhibitory, antiangiogenic and anticancer activity [15-20]. Because of its abundance in European waters and the large amount of biological material available, the lesser spotted dogfish Scyliorhinus canicula (chondrichthyes) could be a useful marine model to further research on bioactive peptides. Previous results have shown that peptides isolated from male dogfish genital tract tissue extracts show a dose-dependent antineoplastic activity on various human cancer cell lines [21]. One of those peptides, QLTPEALADEEEMNALAAR (K092D), inhibited the in vitro proliferation of human cancer cell lines HT-29 (human colon adenocarcinoma; IC50 of $1.79 \mu \mathrm{g} / \mu \mathrm{L}$ ), NCI H69 (human carcinoma, small cell lung cancer; IC25 of $1.25 \mu \mathrm{g} / \mu \mathrm{L}$ ) and CCRF CEM (Human Caucasian acute lymphoblastic leukaemia; IC50 of $2.24 \mu \mathrm{g} / \mu \mathrm{L}$ ). K092D also showed in vivo inhibition of HT-29-derived tumor in Nude mice model (52\% of tumor volume decrease observed at day 22 after a 5-day daily $60 \mathrm{mg} / \mathrm{kg}$ peptide intravenous injection) without presenting acute toxicity (tested up to $400 \mathrm{mg} / \mathrm{kg}$ ) or mutagenic effect (Ames assay) on normal cells [21].

The purpose of this work was to test whether the pyroglutamate-modified K092D peptide (pE-K092D), which is spontaneously obtained from K092D in solution (mass spectrometry analysis, data not shown), shows an efficiency on prostate cancer cells (MDA-Pca-2b cell line), prostate cancer being one of the most common cancers in men. In order to understand how pE-K092D is able to inhibit in vitro growth of the MDA-Pca- $2 \mathrm{~b}$ cell line, we first realized a kinetic study from $6 \mathrm{~h}$ to $96 \mathrm{~h}$ post-treatment to evidence the first noticeable effects. We then studied cell proliferation and cell death mechanisms by flow cytometry and cytoskeleton integrity, and cell characteristics by immunofluorescence. Finally, we investigated the cellular localization of the peptide by subcellular fractionation. Our results have shown that pE-K092D induced early cytoskeleton perturbation, inhibition of autophagy, inhibition of cell proliferation and, at the end, non-apoptotic cell death mechanisms (membrane destabilization and necrosis). All of these mechanisms seem to be contributive to the MDA-Pca-2b growth inhibition by a predominant cytostatic fate. Finally, this work proposes that dogfish tissues are of high interest in finding bioactive peptides presenting high efficiency within short treatment time.

\section{Results}

\subsection{Decrease in Mitochondrial Activity and Cell Number Was Reported in pE-K092D-Treated Human Prostate} Cancer Cells

The mitochondrial potential of the cell culture was tested at $6 \mathrm{~h}, 12 \mathrm{~h}, 24 \mathrm{~h}, 48 \mathrm{~h}, 72 \mathrm{~h}$ and $96 \mathrm{~h}$ post-treatment (hpt) on cells grown with: (i) culture media, (ii) culture media and ammonium bicarbonate $(0.01 \mathrm{M})$ and (iii) culture media and pE-K092D dissolved in $0.01 \mathrm{M}$ ammonium bicarbonate at the final concentration corresponding to the IC50. This assay showed gradual increase of the mitochondrial activity in both controls, even if ammonium bicarbonate treatment induced a lower activity compared to culture media conditions, reflecting the cell proliferation over the considered time period. A significant decrease by half of the mitochondrial activity for pE-K092D-treated cells compared to the ammonium bicarbonate control was observed at each time, from $6 \mathrm{hpt}(0.123 \pm 0.014$ for treated vs. $0.178 \pm 0.022$ for control $)$ and until $96 \mathrm{hpt}(0.432 \pm 0.023 \mathrm{~nm}$ for treated vs. $0.904 \pm 0.058$ for control) (Figure 1A). Furthermore, microscopic observations at each treatment time showed that peptide-treated cells presented a decrease in cell number as well as a low rate of cellular fragments and cell death corpus, as illustrated at $6 \mathrm{hpt}$ and $48 \mathrm{hpt}$ (Figure 1B). Peptide-treated cells also presented more round suspended cells and less adherent cells at $6 \mathrm{hpt}$ and $48 \mathrm{hpt}$, as illustrated by inserts in Figure 1B. 


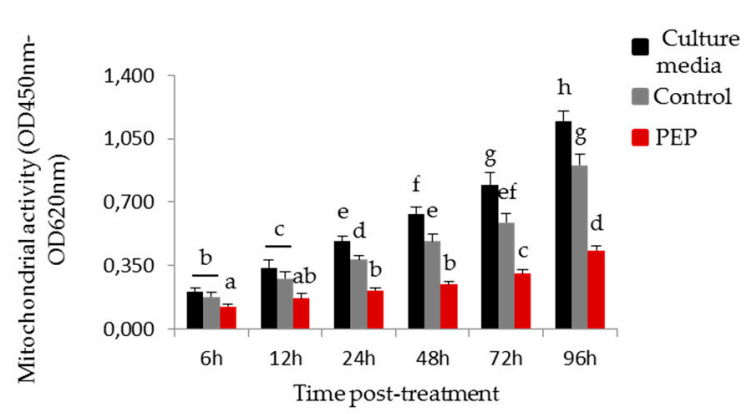

(A)

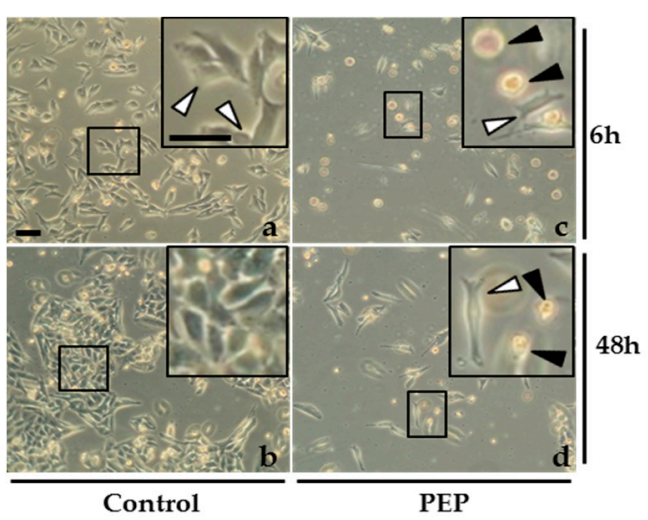

(B)

Figure 1. MDA-Pca-2b cells treated with pE-K092D. (A) Mitochondrial activity measured using the Wst-1 colorimetric assay (OD $450 \mathrm{~nm}-\mathrm{OD} 620 \mathrm{~nm}$ ) at $6 \mathrm{~h}, 12 \mathrm{~h}, 24 \mathrm{~h}, 48 \mathrm{~h}, 72 \mathrm{~h}$ and $96 \mathrm{~h}$ post-treatment for three different conditions of cell culture: culture media (black bars), culture media with $0.01 \mathrm{M}$ ammonium bicarbonate (control, grey bars), culture media with pE-K092D at $1.6 \mu \mathrm{g} / \mu \mathrm{L}$ in $0.01 \mathrm{M}$ ammonium bicarbonate (red bars). Statistical analysis were performed using the Mann and Whitney test $(p<0.01$ between each a to $h$ statistical group). Data were obtained from three independent experiments $(\mathrm{N}=3 ; n=6)$. (B) Representative phase contrast images of control cells $(a, b)$ and pE-K092D-treated cells $(\mathrm{c}, \mathrm{d})$ at $6 \mathrm{~h}(\mathrm{a}, \mathrm{c})$ and $48 \mathrm{~h}(\mathrm{~b}, \mathrm{~d})$ post-treatment. Inserts were focused so as to distinguish adherent cell (white arrow) and round suspended cell (black arrow). Both bars represented $40 \mu \mathrm{m}$.

Those results illustrated the potential antineoplastic effect of pE-K092D on MDA-Pca-2b cells in vitro.

\section{2. pE-K092D Induced a Generation Lag in Human Prostate Cancer Cells}

Cell cycle repartition and corresponding cell generation were investigated on $\mathrm{pE}$-K092D-treated cells and compared to control by flow cytometry at $4 \mathrm{~h}, 8 \mathrm{~h}, 12 \mathrm{~h}, 24 \mathrm{~h}, 48 \mathrm{~h}$ and $72 \mathrm{hpt}$ (Table 1, Figure 2). At $4 \mathrm{hpt}$, peptide-treated cells included fewer in G0/G1 (60.8\% for treated vs. $63.2 \%$ for control) and more cells in G2/M (24.8\% for treated vs. $22.5 \%$ for control). At $8 \mathrm{hpt}$, peptide-treated cells comprised fewer cells in S (14.4\% for treated vs. $16.9 \%$ for control) and more cells in G2/M (21.3\% for treated vs. $18.1 \%$ for control). At $12 \mathrm{hpt}$, peptide-treated cells comprised more cells in G0/G1 (65.2\% for treated vs. $50.7 \%$ for control), fewer cells in S (16.1\% for treated vs. $25.6 \%$ for control) and fewer cells in G2/M ( $20.8 \%$ for treated vs. $23.5 \%$ for control). From $24 \mathrm{hpt} \mathrm{to} 72 \mathrm{hpt}$, no significant difference was observed in cell cycle repartition excepted at $72 \mathrm{hpt}$ with fewer cells in S for pE-K092D-treated cells (10.6\% for treated vs. $14.6 \%$ for control) (Table 1 ).

The cell generation study showed no significant difference between control and peptide-treated cells at $6 \mathrm{hpt}$. At $12 \mathrm{hpt}$, peptide-treated cells showed more cells in generation 0 (g0) (21.6\% for treated vs. $11 \%$ for control), and fewer in generations 1 (g1) $(66.4 \%$ for treated vs. $74.6 \%$ for control) and 2 (g2) $(9.7 \%$ for treated vs. $13.8 \%$ for control) compared to controls (Table 2$)$. At $48 \mathrm{hpt}$, control cells progressed significantly in advanced generations compared to peptide-treated cells which developed higher percentages of cells in generations g0 (11.3\% for treated vs. $1.1 \%$ for control), g1 (29.6\% for treated vs. $17.1 \%$ for control) and g2 (26.5\% for treated vs. $22.0 \%$ for control) and lower percentages of cells in advanced generations g3 $(29.0 \%$ for treated vs. $46.5 \%$ for control) and g4 (2.2\% for treated vs. $13 \%$ for control) (Table 2, Figure 3). 
Table 1. Cell cycle repartition in G0/G1, S and G2/M (\%).

\begin{tabular}{|c|c|c|c|c|c|c|c|c|c|c|c|c|}
\hline & \multicolumn{2}{|c|}{$4 \mathrm{~h}$} & \multicolumn{2}{|c|}{$8 \mathrm{~h}$} & \multicolumn{2}{|c|}{$12 \mathrm{~h}$} & \multicolumn{2}{|c|}{$24 \mathrm{~h}$} & \multicolumn{2}{|c|}{$48 \mathrm{~h}$} & \multicolumn{2}{|c|}{$72 \mathrm{~h}$} \\
\hline & Control & PEP & Control & PEP & Control & PEP & Control & PEP & Control & PEP & Control & PEP \\
\hline G0/G1 & $63.20 \pm 1.41$ & $60.78 \pm 0.98^{*}$ & $64.92 \pm 1.71$ & $64.24 \pm 0.54$ & $50.70 \pm 2.99$ & $65.22 \pm 1.71$ * & $57.11 \pm 1.78$ & $55.82 \pm 6.29$ & $67.25 \pm 3.49$ & $71.10 \pm 6.02$ & $68.83 \pm 3.30$ & $72.63 \pm 0.76$ \\
\hline $\mathrm{S}$ & $13.22 \pm 1.28$ & $13.49 \pm 1.51$ & $16.90 \pm 0.91$ & $14.36 \pm 0.54 *$ & $25.62 \pm 0.13$ & $16.06 \pm 0.14 *$ & $16.75 \pm 1.23$ & $16.77 \pm 2.59$ & $14.36 \pm 1.03$ & $11.34 \pm 2.88$ & $14.61 \pm 0.85$ & $10.62 \pm 2.35 *$ \\
\hline G2/M & $22.50 \pm 0.01$ & $24.82 \pm 0.53 *$ & $18.06 \pm 1.07$ & $21.27 \pm 0.02 *$ & $23.53 \pm 2.94$ & $20.81 \pm 3.48^{*}$ & $26.03 \pm 2.55$ & $27.06 \pm 4.07$ & $18.28 \pm 3.20$ & $17.13 \pm 3.62$ & $16.06 \pm 2.61$ & $16.22 \pm 1.87$ \\
\hline
\end{tabular}

Cell cycle repartition was measured by flow cytometry after propidium iodide (PI) staining at $4 \mathrm{~h}, 8 \mathrm{~h}, 12 \mathrm{~h}, 24 \mathrm{~h}, 48 \mathrm{~h}$ and $72 \mathrm{~h}$ post-treatment for three independent experiments on control cells and peptide-treated cells (PEP). Results in percentages were represented by mean \pm SD and statistical analysis was performed using the Mann and Whitney test $\left.{ }^{*} p<0.05\right)$.

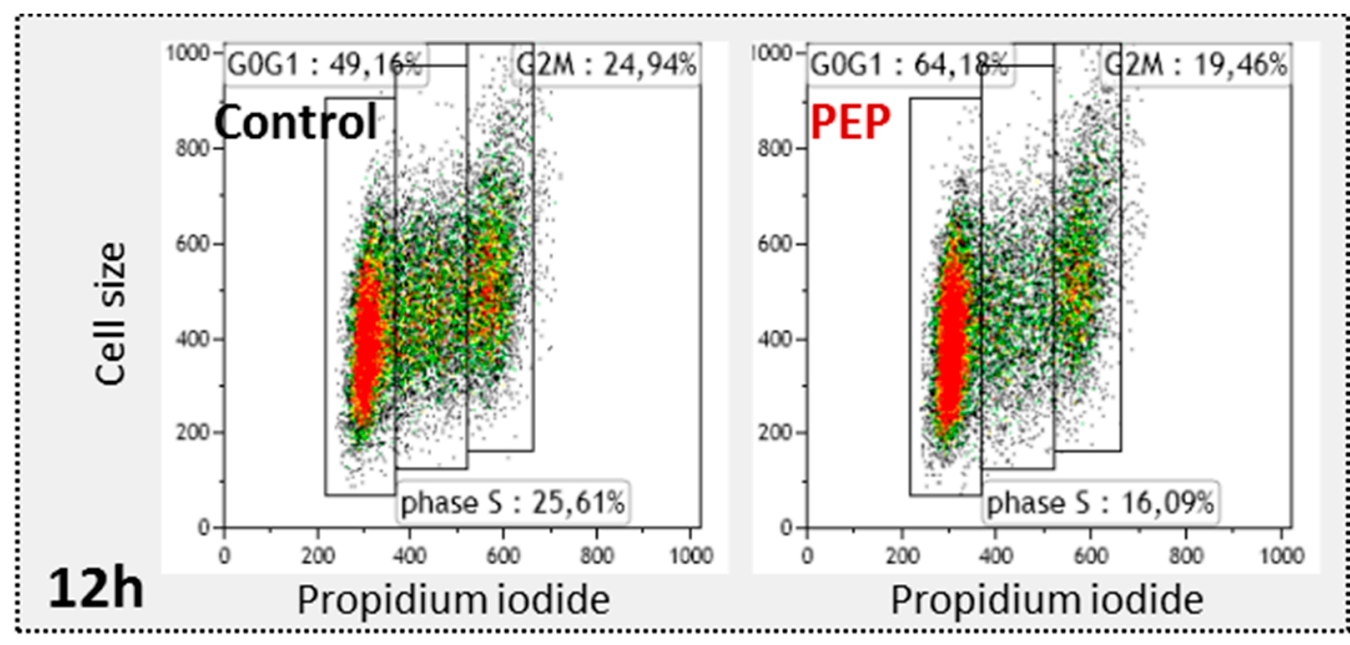

Figure 2. Representative flow cytometry data at $12 \mathrm{hpt} \mathrm{for} \mathrm{control} \mathrm{and} \mathrm{pE-K092D-treated} \mathrm{cells} \mathrm{(PEP)}$ 
Table 2. Cell generation (\%).

\begin{tabular}{ccccccc}
\hline & \multicolumn{2}{c}{$\mathbf{6 h}$} & \multicolumn{2}{c}{$\mathbf{1 2} \mathbf{h}$} & \multicolumn{2}{c}{$\mathbf{4 8} \mathbf{h}$} \\
& Control & PEP & Control & PEP & Control & PEP \\
\hline g0 & $17.5 \pm 0.4$ & $19.8 \pm 1.2$ & $11.0 \pm 0.8^{*}$ & $21.0 \pm 1.3$ & $1.1 \pm 0.0^{*}$ & $11.3 \pm 2.4$ \\
g1 & $73.6 \pm 1.6$ & $72.7 \pm 1.8$ & $74.6 \pm 2.4^{*}$ & $66.4 \pm 1.8$ & $17.1 \pm 1.2^{*}$ & $29.6 \pm 1.9$ \\
g2 & $8.0 \pm 0.9$ & $7.6 \pm 0.4$ & $13.8 \pm 1.2 *$ & $9.7 \pm 0.9$ & $22.0 \pm 1.3^{*}$ & $26.5 \pm 1.4$ \\
g3 & $0.3 \pm 0.1$ & $0.4 \pm 0.1$ & $0.8 \pm 0.1$ & $0.6 \pm 0.2$ & $46.5 \pm 2.6^{*}$ & $29.0 \pm 1.5$ \\
g4 & $0.1 \pm 0.0$ & $0.4 \pm 0.1$ & $0.1 \pm 0.0$ & $0.2 \pm 0.0$ & $13.0 \pm 0.4^{*}$ & $2.2 \pm 0.9$ \\
\hline
\end{tabular}

Percentage of cells in four generations (g0 to g4) was measured at $6 \mathrm{~h}, 12 \mathrm{~h}$ and $48 \mathrm{~h}$ post-treatment for two independent experiments in control cells and pE-K092D-treated cells (PEP) using Carboxy Fluorescein Succinimidyl Ester (CFSE) assay and flow cytometry analysis. Results were represented by mean \pm SD and statistical analysis was performed using the Mann and Whitney test $\left.{ }^{*} p<0.05\right)$.

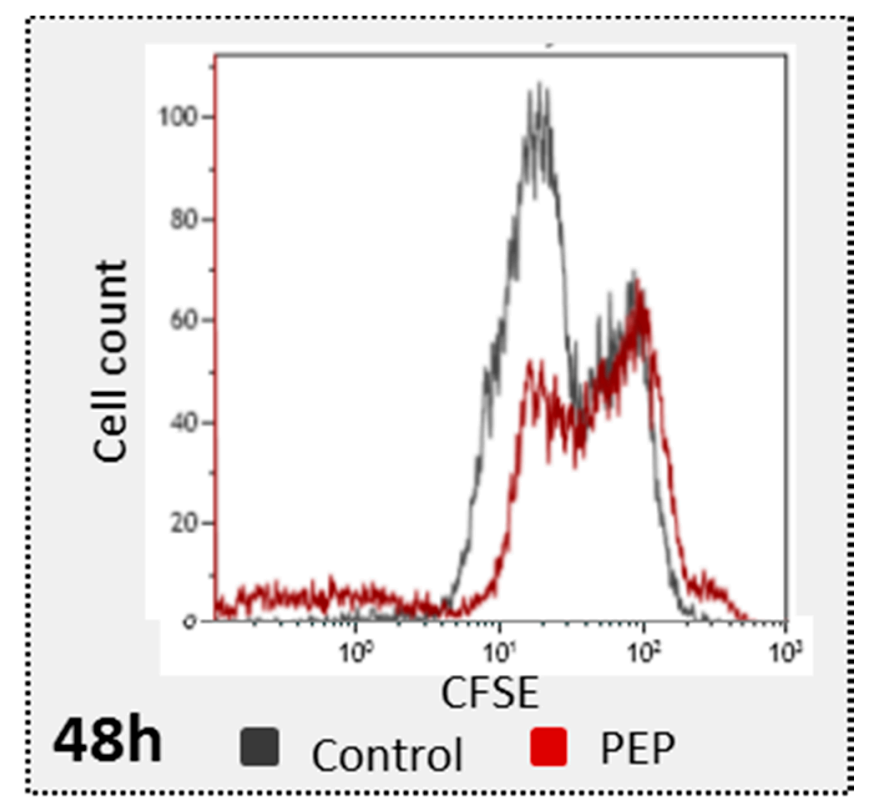

Figure 3. Representative flow cytometry data at $48 \mathrm{hpt}$ for control and pE-K092D-treated cells (PEP).

Those studies have shown that pE-K092D induced a durable antiproliferative effect starting at 12 hpt on MDA-PCa-2b cells.

\section{3. pE-K092D Induced Early Autophagy Inhibition Followed by Membrane Destabilization and Necrosis}

In order to clarify the mechanism involved in the significant antiproliferative effect of $\mathrm{pE}-\mathrm{K} 092 \mathrm{D}$ observed at $12 \mathrm{hpt}$, autophagy capacity of peptide-treated cells at 4, 6 and $12 \mathrm{hpt}$ (Figure 4A,B) were further researched and death mechanism like apoptosis, necrosis and membrane destabilization at 24, 48 and $72 \mathrm{hpt}$ (Table 3, Figure 5A,B) were investigated. Peptide-treated cells presented an early decrease of the percentage of autophagosomes observed at $6 \mathrm{hpt}(42.3 \%$ of the control, Figure $4 \mathrm{~A})$, and no difference between treated and controls was observed at 4 and $12 \mathrm{hpt}$. A significant increase of destabilized membranes was observed in treated cells at $24 \mathrm{hpt}$ ( $6.9 \%$ for treated vs. $3.0 \%$ for control),

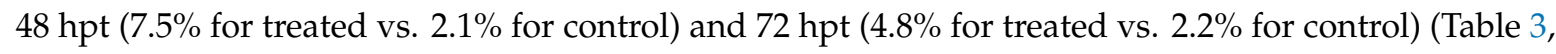
Figure 5A). In parallel, the level of destroyed membranes also increased at $24 \mathrm{hpt}(9.1 \%$ for treated vs.

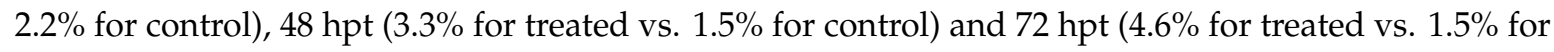
control) (Table 3, Figure 5A). No difference between treated cells and controls was observed for the DNA fragments and for apoptosis, however a rise in necrosis levels was observed at $48 \mathrm{hpt}(5.2 \%$ for treated vs. $2.3 \%$ for control) and $72 \mathrm{hpt} \mathrm{(6.4 \%} \mathrm{for} \mathrm{treated} \mathrm{vs.} 4.0 \%$ for control) (Table 3, Figure 5B). 


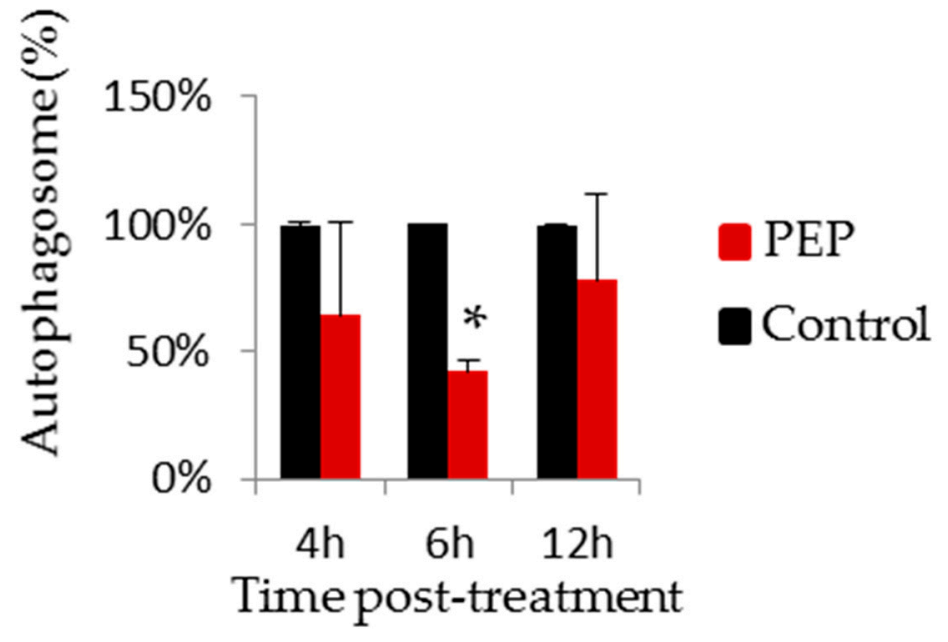

(A)

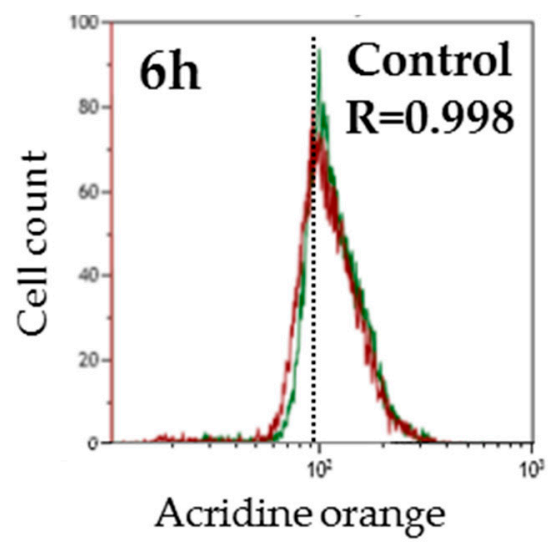

Acridine orange

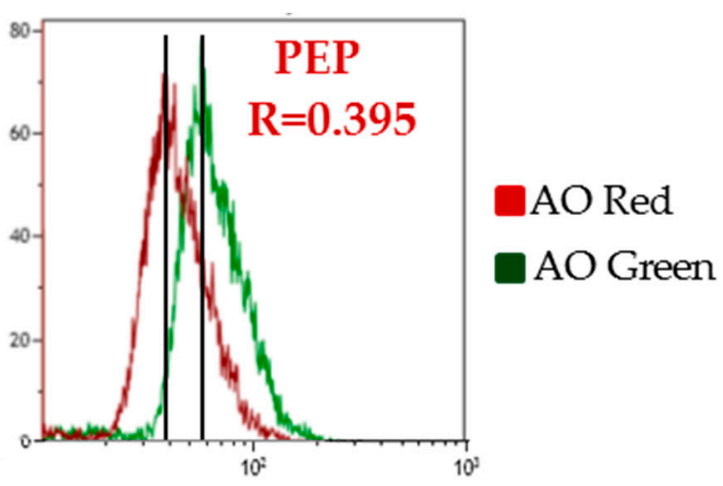

Acridine orange

(B)

Figure 4. Autophagosomes analysis. (A) Percentages of autophagosomes in pE-K092D-treated cells (red bars) normalized to control cells $(100 \%$, black bars) as measured by flow cytometry using acridine orange assay $(\mathrm{AO})$ at $4 \mathrm{~h}, 6 \mathrm{~h}$ and $12 \mathrm{~h}$ post-treatment. Statistical analysis was performed using the Mann and Whitney test $(p<0.01$, star indicates significant differences between peptide-treated cells and control). Data was obtained from two independent experiments. (B) Representative flow cytometry data at $6 \mathrm{hpt}$ for control and peptide-treated cells with corresponding $\mathrm{R}$ value of autophagosomes percentages ( $\mathrm{R}=$ red fluorescence due to $\mathrm{AO}$ binding to autophagosomes / green fluorescence due to AO binding to nucleic acids).

These results showed that pE-K092D triggered an early onset of autophagy inhibition and then induced cell death by membrane destabilization and necrosis. 
Table 3. Membrane integrity, apoptosis and necrosis (\%).

\begin{tabular}{ccccc}
\hline Study & Samples & $\mathbf{2 4} \mathbf{h}$ & $\mathbf{4 8} \mathbf{h}$ & $\mathbf{7 2} \mathbf{~ h}$ \\
\hline Destabilized & Control & $3.0 \pm 0.4$ & $2.1 \pm 0.4$ & $2.2 \pm 0.8$ \\
membranes & PEP & $6.9 \pm 1.1^{*}$ & $7.5 \pm 2.3^{*}$ & $4.8 \pm 0.4^{*}$ \\
\hline Destroyed & Control & $2.2 \pm 0.7$ & $1.5 \pm 0.1$ & $1.5 \pm 0.4$ \\
membranes & PEP & $9.1 \pm 3.7^{*}$ & $3.3 \pm 0.3^{*}$ & $4.6 \pm 0.4^{*}$ \\
\hline \multirow{2}{*}{ Cell Fragments } & Control & $3.7 \pm 1.1$ & $3.9 \pm 0.2$ & $4.0 \pm 2.6$ \\
& PEP & $5.1 \pm 1.4$ & $5.3 \pm 2.3$ & $5.6 \pm 2.4$ \\
\hline \multirow{2}{*}{ Apoptosis } & Control & $2.3 \pm 0.8$ & $1.5 \pm 0.5$ & $1.9 \pm 1.1$ \\
& PEP & $2.9 \pm 1.3$ & $2.8 \pm 1.5$ & $2.7 \pm 0.7$ \\
\hline \multirow{2}{*}{ Necrosis } & Control & $3.1 \pm 0.5$ & $2.3 \pm 0.0$ & $4.0 \pm 1.2$ \\
& PEP & $5.4 \pm 2.6$ & $5.2 \pm 1.9 *$ & $6.4 \pm 1.1 *$ \\
\hline
\end{tabular}

Percentages of destabilized membranes, destroyed membranes, cell fragments, apoptosis and necrosis in control and $\mathrm{pE}-\mathrm{K} 092 \mathrm{D}$-treated cells (PEP) at $24 \mathrm{~h}, 48 \mathrm{~h}$ and $72 \mathrm{~h}$ post-treatment. Data obtained from three independent experiments were represented by mean $\pm \mathrm{SD}$, and * indicates significant differences between control and peptide-treated cells (Mann and Whitney test; $p<0.05$ ).
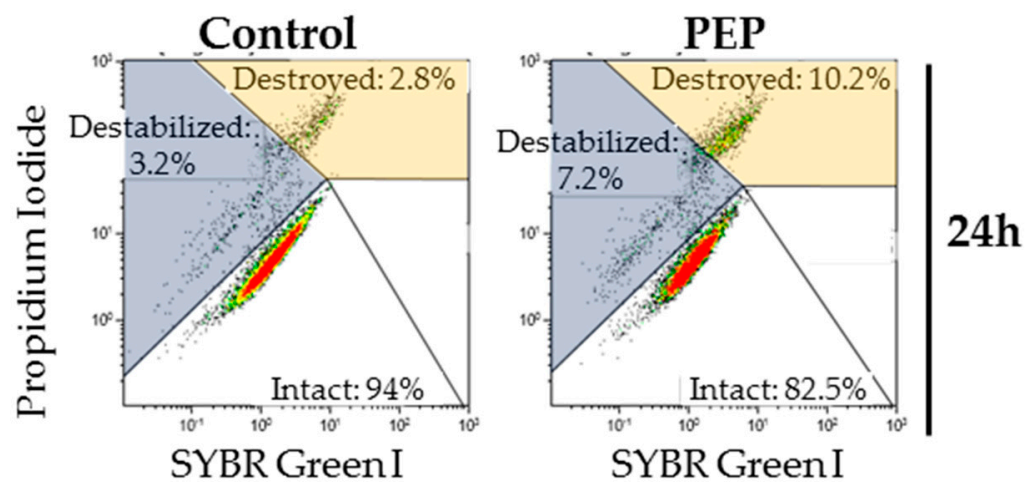

(A)
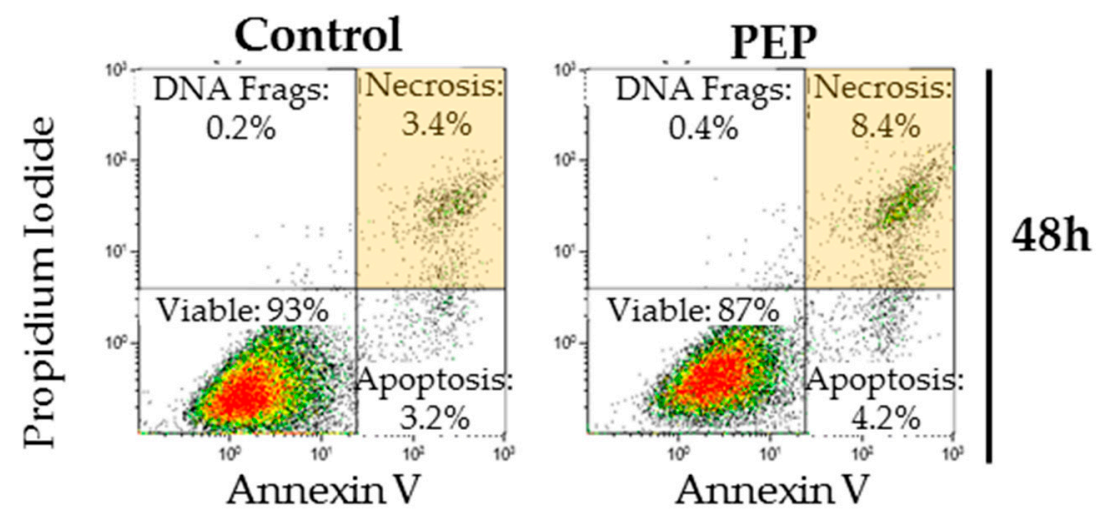

(B)

Figure 5. (A) Representative flow cytometry propidium iodide (PI)/SYBR Green I data for membrane integrity study at $24 \mathrm{~h}$ post-treatment illustrating the increase in destabilized and destroyed membranes in pE-K092D-treated cells. (B) Representative flow cytometry PI/annexin V data for cell death study at $48 \mathrm{~h}$ post-treatment illustrating the increase of necrosis in peptide-treated cells compared to control cells. 


\section{4. pE-K092D Induced Early Cytoskeleton Perturbations with Particular Features}

Actin filaments and microtubules as well as nuclei were observed at 6 and 48 hpt (Figures 6 and 7). Comparatively to controls, at $6 \mathrm{hpt}$ the pE-K092D-treated cell population presented more single cells ( $52 \%$ for treated vs. $38 \%$ for control) and more paired cells ( $31.5 \%$ for treated vs. $21.5 \%$ for control) whereas fewer clusters of cells were observed (16.5\% for treated vs. $40.5 \%$ for control) (Figure $6 \mathrm{~A}-\mathrm{C}$ ). More round cells (34.6\% for treated vs. $13.3 \%$ for control) and fewer adherent and spread cells (11\% for treated vs. $31.6 \%$ for control) were observed at $6 \mathrm{hpt}$ in pE-K092D-treated cells than in controls (Figure 6A-C). At $48 \mathrm{hpt}$, the peptide-treated cell population was characterized by a larger number of chained cells $(41.3 \%$ for treated vs. $1.8 \%$ for control, Figure $6 \mathrm{~A}, \mathrm{D}, \mathrm{E})$ and nuclear fragmentation $(12.6 \%$ for treated vs. $1.4 \%$ for control, Figure $6 \mathrm{~F}$ ).

(A)

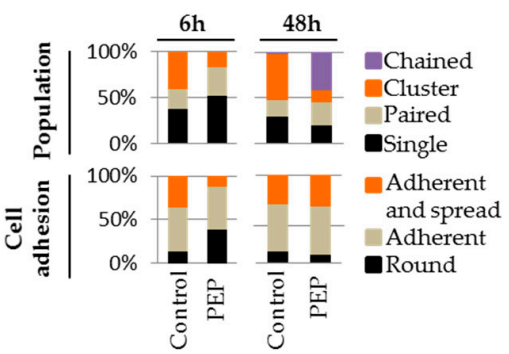

(F)
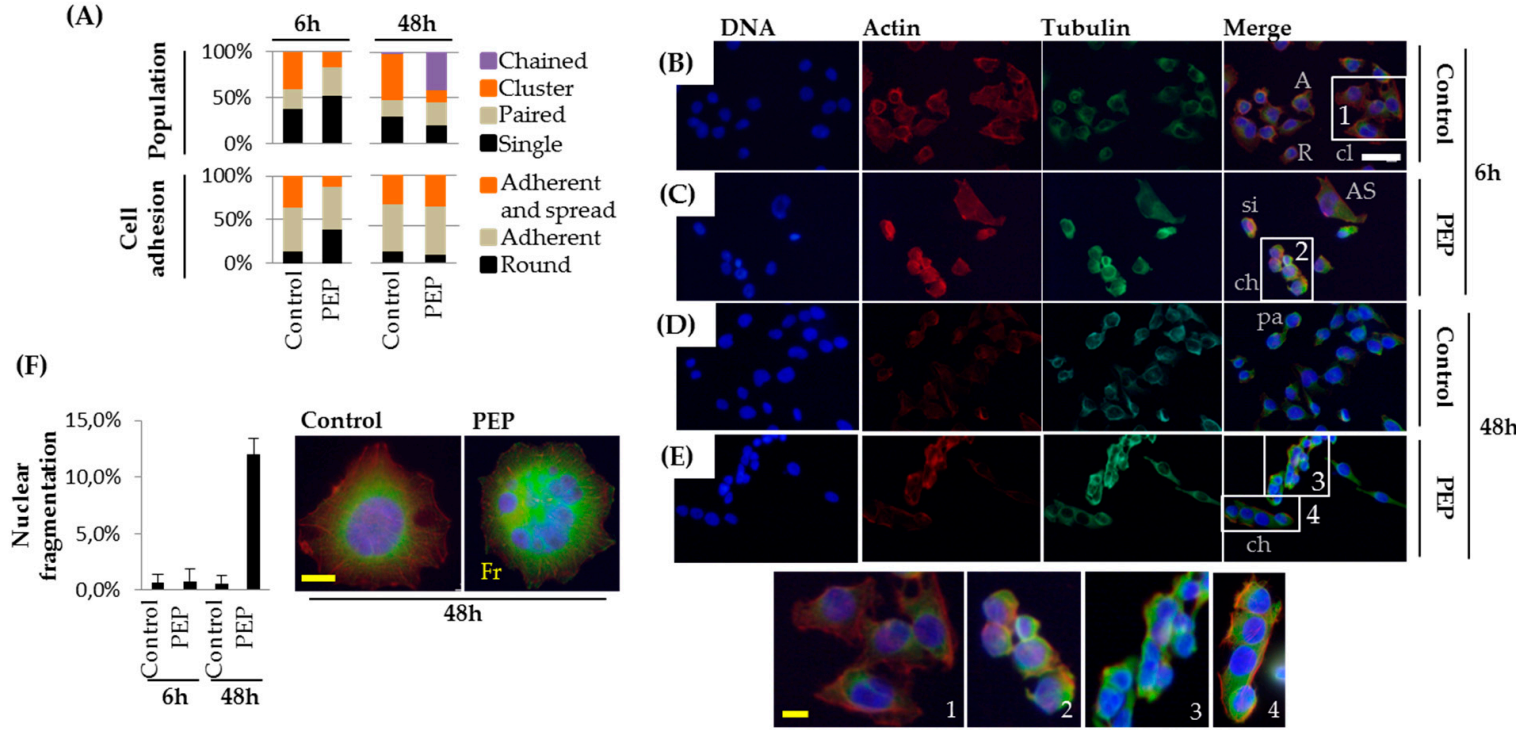

Figure 6. Adherence capacity, chained cells formation and nuclear fragmentation in MDA-Pca-2b cells. (A) Percentages of cell distribution based on their morphological characteristics in control and pE-K092D-treated cell populations (PEP) at $6 \mathrm{~h}$ and $48 \mathrm{~h}$ post-treatment. (B-E) Representative cytofluorescence with DAPI (DNA, blue), phalloidin (actin, red) and anti-tubulin antibody (tubulin, green) of control (B, D) and peptide-treated (C, E) cells at $6 \mathrm{hpt}(\mathrm{B}, \mathrm{C})$ and $48 \mathrm{hpt}(\mathrm{D}, \mathrm{E})$ are represented. si: single cell, pa: paired cells, cl—clusters of cells, ch—chained cells, $\mathrm{R}$-round cells, A-adherent cells, AS-adherent and spread cells. Inserts (numbered 1-4) highlighted the difference between a cluster (1) and chained cells (2-4). The yellow scale bar represents $12.5 \mu \mathrm{m}$ and the white bar $40 \mu \mathrm{m}$. (F) Percentages of cells with fragmented nucleus (Fr) in control and peptide-treated cell populations at $6 \mathrm{~h}$ and $48 \mathrm{~h}$ post-treatment with representative cytofluorescence. The yellow bar represents $12.5 \mu \mathrm{m}$. 
(A)

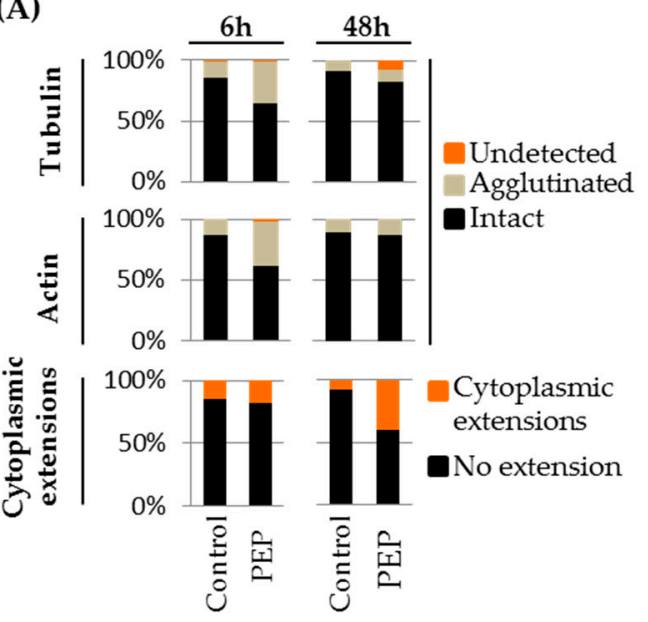

(B)
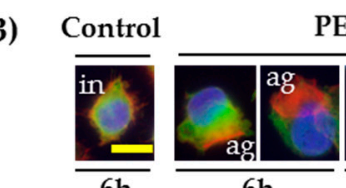

PEP

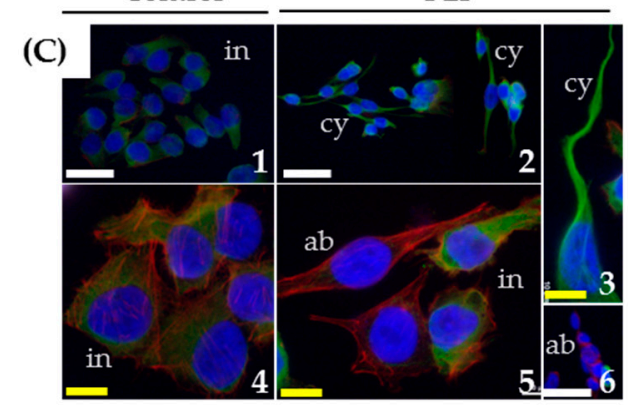

Figure 7. Alteration of actin and tubulin cytoskeletons and cytoplasmic extensions in MDA-Pca-2b cells. (A) Percentages of cell distribution based on their characteristics for microtubules, microfilaments and cytoplasmic extensions in control and pE-K092D-treated cell populations at $6 \mathrm{~h}$ and $48 \mathrm{~h}$ post-treatment. (B) Representative cytofluorescence with DAPI (DNA, blue), phalloidin (actin, red) and anti-tubulin antibody (tubulin, green) of control and pE-K092D-treated cells at $6 \mathrm{~h}$ and $48 \mathrm{~h}$ post-treatment showing differences between intact cytoskeleton (in) and agglutinated cytoskeleton (ag) in single isolated cells. Yellow scale bar equals $12.5 \mu \mathrm{m}$. (C) Representative cytofluorescence with DAPI (DNA, blue), phalloidin (actin, red) and anti-tubulin antibody (tubulin, green) of control $(1,4)$ and pE-K092D-treated cells $(2-3$, 5-6) at $48 \mathrm{~h}$ post-treatment showing differences between cells with intact cytoskeleton (in, 1, 4), cells with cytoplasmic extensions (cy, 2) and cells without detectable microtubules (ab, 5). Focus on cell with aberrant cytoplasmic extension (3) and chained cells without tubulin staining (6). The yellow bar is $12.5 \mu \mathrm{m}$ and white bar $40 \mu \mathrm{m}$.

Investigation of cytoskeleton modifications by cytofluorescence observations made it possible to report agglutinations of microtubules (34.6\% for treated vs. $13.3 \%$ for control) and of actin filaments (37\% for treated vs. 13.3\% for control) in pE-K092D-treated cells at 6 hpt (Figure 7A,B). The increase in percentage of cells presenting cytoplasmic extensions was also noticed at $48 \mathrm{hpt}$ for pE-K092D-treated cells $(39.5 \%)$ comparatively to control (7.3\%) (Figure $7 \mathrm{~A}-\mathrm{C})$. The loss of detection of microtubules in $7.8 \%$ of pE-K092D-treated cells at $48 \mathrm{hpt}$ was also reported (Figure 7A-C).

Mitotic spindle orientations in the plane of the cell-culture dishes were observed at $6 \mathrm{hpt}$ (Figure 8A,B). In pE-K092D-treated cells, 75\% of cells in metaphase presented a perpendicularly or a variable spindle orientation in the $x-y$ plane at $6 \mathrm{hpt}$. In contrast, only cells in telophase resulting of a planar orientation of the mitotic spindle were observed in control cells. Interestingly, subcellular fractionation (results not shown) indicated that the peptide was found to be in a five-fold higher concentration in the fraction containing nuclei and cytoskeleton than in the others at $6 \mathrm{hpt}$ and $48 \mathrm{hpt}$.

These results show that pE-K092D has affected actin and tubulin cytoskeletons, cell adherence, cell morphology and the cell population characteristics with, among others, a misorientation of the mitotic spindle. 
(A)
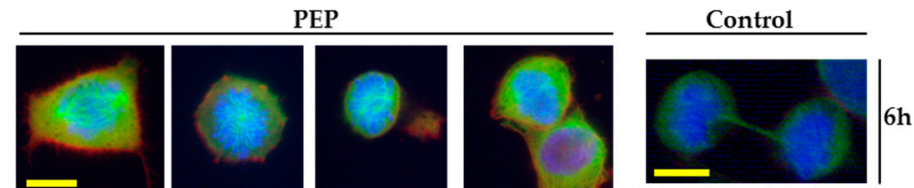

(B)
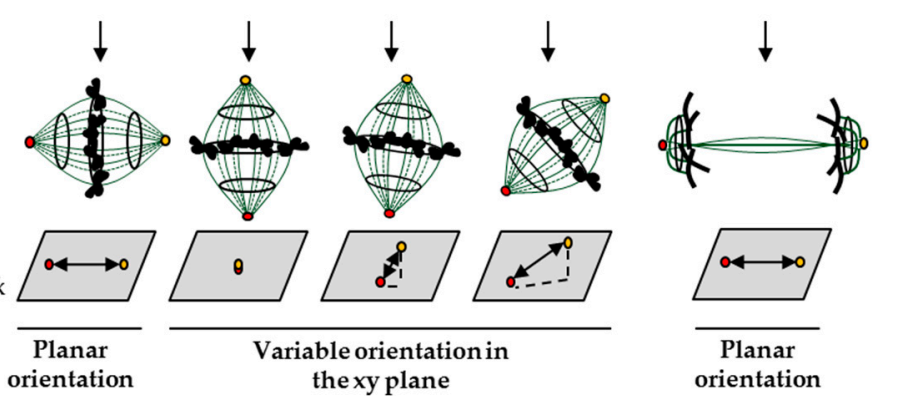

Figure 8. Mitotic spindle orientations in MDA-Pca-2b cells at $6 \mathrm{~h}$ post-treatment with $\mathrm{pE}-\mathrm{K} 092 \mathrm{D}$ (PEP). (A) Representative cytofluorescence of control and treated cells. Tubulin, actin and DNA were stained using anti-tubulin antibody (green), phalloidin (red) and DAPI (blue), respectively. (B) Corresponding scheme of the mitotic spindle (green bars) orientation with chromosomes (black) in the $x-y-z$ axes on the culture plastic area (grey box), yellow and red circles represent the spindle poles. The yellow bar equals $12.5 \mu \mathrm{m}$.

\section{Discussion}

This study reported that the first effects observed for $\mathrm{pE}-\mathrm{K} 092 \mathrm{D}$ treatment on MDA-Pca-2b prostate cancer cells were an inhibition of autophagy and a perturbation of the cytoskeleton including a non-planar orientation of the mitotic spindle. These effects were followed by a durable slowing-down of the cell cycle. Later on, other effects were reported such as, to a lesser extent, an increase of cell membrane destabilization and cell necrosis, cell morphology disorders and nucleus fragmentation.

Autophagy is a complex mechanism allowing organelle and protein turnovers, thereby protecting cells from various stress conditions. In cancer cells, autophagy according to its intensity can promote either cell survival allowing tumor survival and development, or cell death by apoptotic or non-apoptotic cell death (such as necrosis) [22-24]. This dual role of autophagy in cancer can lead to reports where its inhibition, or on the contrary its activation, is associated with a promotion of apoptosis. Thus, prostate cancer cell death through induction of autophagy, apoptosis and necrosis or disturbance of tubulin formation has been reported [25,26]. Conversely, inhibition of autophagy was also correlated with an increase of caspase-dependent apoptosis in various cells such as HeLa or lymphoma cells [27] and sometimes with necrosis in other cells such as human glioblastomes [28]. Our results have shown that autophagy inhibition was observed at $6 \mathrm{hpt}$ on pE-K092D-treated cells but was not maintained and not followed by apoptosis, suggesting that this first effect was transitory. However, late necrosis was observed in pE-K092D-treated cells suggesting that the transitory autophagy inhibition may contribute to non-apoptotic cell death mechanism in MDA-Pca-2b cells.

In light of the various interactions described between the cytoskeleton and autophagy [29], the autophagy inhibition observed on pE-K092D-treated cells could be induced by cytoskeleton perturbations observed at the same time. Indeed, the concomitance between tubulin remodeling and autophagy inhibition has been reported on mouse neural cells [30]. Moreover, the cytoskeleton dynamics and the interactions between its different compounds are of course fundamental during all steps of mitosis such as for the mitotic spindle assembly, the mitotic spindle orientation or for cytokenesis [31]. As reported in many studies on various cancer cell lines, direct perturbation of the depolymerization/polymerization of microtubule induce cell cycle arrest before metaphase and are often associated with mitotic spindle aberrations [32-34]. Thus, the kinetics of observed effects let us hypothesize that the slowing-down of cell cycle was a consequence of the cytoskeleton perturbation. Other cell morphological characteristics similar to those we observed during our study are associated 
to cytoskeleton perturbation such as the chained cell formation in yeast [35] or such cytoplasmic extensions in breast cancer cells over-expressing the guanine nucleotide releasing factor (C3G) [36] or treated with the suberoylanilide hydroxamic acid (SAHA) antineoplastic drug [37]. Moreover, the subcellular fractionation experiment had shown that the peptide was mainly found in the fraction containing nuclei and cytoskeleton, which was consistent with cytoskeleton perturbation. Finally, all of our observations suggest an interaction of pE-K092D with a cytoskeleton element leading to a disruption of multiple cellular processes, including membrane destabilization that could be related to cell cortex perturbation and would finally promote the cell necrosis of some MDA-Pca- $2 \mathrm{~b}$ cells. In parallel, the strong cell cycle slowing-down observed at $12 \mathrm{hpt}$ could be correlated to a cytostatic fate, which was consistent with observations showing the lack of cellular fragments and cell death corpus.

To conclude, pE-K092D is a potential antineoplastic marine peptide which inhibits the growth of MDA-Pca- $2 \mathrm{~b}$ cells in vitro by an original action mechanism with a fast and durable effect leading to various cell dysfunctions. Its main target seems to be a cytoskeleton element whose disruption would induce a strong and precocious cytostatic fate followed by a lighter cytotoxic effect. Further investigations should be performed at the molecular level to confirm these hypotheses and to identify which cytoskeleton element is involved.

\section{Materials and Methods}

\subsection{Cell Culture and Treatment Conditions}

MDA-Pca- $2 \mathrm{~b}$ cell line was established from the bone metastasis of a 63 years old black man with androgen-independent adenocarcinoma of the prostate (cell line obtained from the global bioresource center ATCC; www.atcc.org/). This cell line expresses prostate specific antigen (PSA) and androgen receptor, grows in vitro and in vivo, and is androgen sensitive. MDA-Pca-2b cells were maintained in Ham's F12 media (supplemented with 20\% SVF, $5 \mathrm{mM}$ L-Glu, $10 \mathrm{ng} / \mathrm{mL}$ EGF, hydrocortisone $100 \mathrm{pg} / \mathrm{mL}$ ) at $37^{\circ} \mathrm{C}$ in a $5 \% \mathrm{CO}_{2}$ air incubator. Prior experiments, the cells were grown to about $80 \%$ confluence three times and then exposed to peptide at a concentration corresponding to IC50 $(1.6 \mu \mathrm{g} / \mu \mathrm{L}) . \mathrm{pE}-\mathrm{K} 092 \mathrm{D}$ was synthetized by and purchased from Bionexus company (Strasbourg, France; $95.90 \%$ purity), stored at $-20^{\circ} \mathrm{C}$ and dissolved in bicarbonate ammonium $(0.1 \mathrm{M})$ when needed. Results were compared with those obtained for controls, cells grown in culture media and in culture media with bicarbonate ammonium $(0.1 \mathrm{M})$.

\subsection{Mitochondrial Activity Assay}

Mitochondrial activity was measured by the WST-1 colorimetric assay (Roche; Ref.: 11644807 001) based on the cellular capacity to metabolize the WST-1 by mitochondrial enzymatic complex. Cells were seeded into 96 well-plates (5000 cells/well) and treated in replicates for 6 h, 12 h, 24 h, 48 h, 72 h and $96 \mathrm{~h}$. WST-1 was added as recommended by suppliers and plates were incubated for $2 \mathrm{~h}$ before being analyzed in a spectrophotometer (BioRad; iMark; Marnes-la-Coquette, France). Optical density $(\mathrm{OD})$ at $620 \mathrm{~nm}$, corresponding to background level, was subtracted from OD at $450 \mathrm{~nm}$ corresponding to WST-1 degradation. Statistical analyses were performed using the Mann and Whitney test $(p<0.01)$ on three independent experiments $(\mathrm{N}=3 ; n=9)$.

\subsection{Apoptosis/necrosis and Membranes Integrity Analysis}

Both apoptosis/necrosis and membrane integrity were quantified by flow cytometry using two double stainings: propidium iodide (PI) and annexin V (AV), or PI and sybr green I (SGI) respectively. PI and SGI were both used to stain DNA, but only the SGI could pass through cellular membranes without perforation. Annexin $\mathrm{V}$ allowed apoptosis/necrosis detection by its high affinity to bind phosphatidylserins exposed at the extracellular side of apoptotic cells. Cells were seeded into 24 well-plates $(29,688$ cells/well) and treated in replicates for $6 \mathrm{~h}, 12 \mathrm{~h}, 24 \mathrm{~h}, 48 \mathrm{~h}$ and $72 \mathrm{~h}$. Cells were then trypsinized $(170 \mathrm{U} / \mathrm{mL})$, washed and then stained in two ways: (i) apoptosis/necrosis analysis using PI 
and AV (both 1:500, as described by suppliers); (ii) membrane integrity analysis using SGI at 1:1 $\times 10^{6}$ and PI at 1:500 with an incubation time of $30 \mathrm{~min}$ in the dark. Samples were then analyzed by flow cytometry (Gallios cytometer, Beckman Coulter Life Sciences, Villepinte, France). For each sample, 20,000 events were counted and statistical analyses were performed on three independent experiments using the Mann and Whitney test $(p<0.05)(\mathrm{N}=3 ; n=6)$.

\subsection{Cell Cycle Analysis}

Cell cycle repartition was investigated at $4 \mathrm{~h}, 8 \mathrm{~h}, 12 \mathrm{~h}, 24 \mathrm{~h}, 48 \mathrm{~h}$ and $72 \mathrm{~h}$ by flow cytometry with PI staining. On ethanol fixed cells, PI staining allowed DNA quantification corresponding to cell populations in G0/G1 (2C); S (between 2C and 4C) or G2/M (4C). Cells were seeded in replicates into 24 well-plates $(29,688$ cells/well) and treated. Then, they were trypsinized $(170 \mathrm{U} / \mathrm{mL})$, washed, fixed and stored in ethanol $70 \%$ at $-20^{\circ} \mathrm{C}$. Before flow cytometry analysis, cells were washed at $37^{\circ} \mathrm{C}$ and stained for $30 \mathrm{~min}$ in dark conditions with PI as described by suppliers. For each sample, 20,000 events were counted and statistical analysis was performed on three independent experiments using the Mann and Whitney test $(p<0.05)(\mathrm{N}=3 ; n=6)$.

\subsection{Cell Generation Study}

Cell generation was determined at $6 \mathrm{~h}, 12 \mathrm{~h}$ and $48 \mathrm{~h}$ post-treatment using Carboxy Fluorescein Succinimidyl Ester assay (CFSE) with flow cytometry analysis (Gallios cytometer with Kaluza licence, Beckman Coulter Life Sciences, Villepinte, France). CFSE was sequestrated in intracellular compartment and at the cell surface during treatment time and was equally subdivided into the 2 daughter cells after mitosis. So, the first generation, corresponding to seeded cells (called g0), showed the maximum of fluorescence and for each following generation, fluorescence was divided by two. Cells were stained with $5 \mu \mathrm{M}$ CFSE for 10 minutes at $37^{\circ} \mathrm{C}$, washed with PBS, seeded in replicates into 24 well-plates $(29,688$ cells/well $)$ and treated. Cells were then trypsinized $(170 \mathrm{U} / \mathrm{mL})$, washed, and analyzed by flow cytometry. For each sample, 50,000 events were counted and statistical analyses were performed on two independent experiments using the Mann and Whitney test $(p<0.05)(\mathrm{N}=2 ; n=4)$.

\subsection{Autophagy Measurement}

Autophagy, directly correlated with the quantity of autophagosomes, was investigated at 4, 6 and $12 \mathrm{hpt}$ using acridine orange assay and flow cytometry analysis. Acridine orange was used to stain autophagosome organelles (red fluorescence) and nucleic acids in cytoplasm and nucleus (green fluorescence). The percentage of autophagosomes ( $R ; R=100 \%$ for controls) was determined by normalization of the red fluorescence by the green fluorescence: $\mathrm{R}=$ FL3 INT / FL1 INT. Cells were seeded in replicates into 24 well-plates $(29,688$ cells/well) and treated. Cells were then stained with $\mathrm{AO}(5 \mu \mathrm{g} / \mathrm{mL})$ for 10 minutes at $37^{\circ} \mathrm{C}$, trypsinized $(170 \mathrm{U} / \mathrm{mL})$, washed and analyzed by flow cytometry. For each sample, 20,000 events were counted and statistical analysis was performed on two independent experiments using the Mann and Whitney test $(p<0.05)(\mathrm{N}=2 ; n=4)$.

\subsection{Immunocytochemistry Analysis}

Tubulin and actin cytoskeletons were observed at 6 and $48 \mathrm{hpt}$ using a mouse anti-tyrosine tubulin antibody (Sigma: T9028; L'Isle d'Abeau Chesnes, France) and phalloidin staining $(5 \mu \mathrm{g} / \mathrm{mL})$, respectively. Cells were seeded in replicates on microscope cover glass slides into 24 well-plates $(29,688$ cells/well) and treated. Cells were then fixed in $4 \%$ PFA for 10 minutes, washed in $1 \%$ BSA-PBS solution, incubated $1 \mathrm{~h}$ with both phalloidin (1:200) and anti-tubulin (1:200), washed, incubated with secondary antibody (1:500; goat anti-mouse IgG Alexa fluor 488; Invitrogen: A11001) for $1 \mathrm{~h}$ in the dark and washed. Cover glass slides were finally mounted on microscope slides with a mounting solution containing DAPI (Prolong gold antifade with DAPI; Invitrogen P36935). Observations, pictures and merge were taken with an Eclipse 80i microscope coupled to a DXM1200-C camera (Nikon, Champigny 
sur Marne, France). Quantification was made by taking 25 pictures per sample. Using replicates, each independent experiment comprised 50 pictures for which cells were counted using a quantification grid.

\subsection{Subcellular Fractionation}

The cellular localization of pE-K092D was investigated at $6 \mathrm{hpt}$ and $48 \mathrm{hpt}$ by mass spectrometry after subcellular fractionation. Cells were first collected, homogenized using a syringe with needle in a $0.25 \mathrm{M}$ isotonic saccharose solution and short spin centrifuged. Pellets corresponding to undestroyed cells were isolated and supernatants were centrifuged $20 \mathrm{~min}$ at $1000 \mathrm{~g}$ and $4{ }^{\circ} \mathrm{C}$ in order to separate nuclei and cytoskeleton elements. Those pellets were then isolated and supernatants were centrifuged for another $20 \mathrm{~min}$ at $1,000 \mathrm{~g}$ and $4{ }^{\circ} \mathrm{C}$ to isolate pellets containing organelles such as mitochondria, lysosomes and peroxysomes. Supernatants were finally centrifuged for $1 \mathrm{~h}$ at $100,000 \mathrm{~g}$ and $4{ }^{\circ} \mathrm{C}$ and as a result pellets corresponded to membranes and microsomes whereas supernatants contained cytosolic fraction with few polysomes. All pellets were then suspended in a $0.1 \%$ TFA-acetonitrile solution, stored at $-80^{\circ} \mathrm{C}$ and analyzed by mass spectrometry.

Author Contributions: Conceptualization, A.B. (Adrien Bosseboeuf), A.B. (Amandine Barron), E.D. and P.A.; methodology, A.B. (Adrien Bosseboeuf), A.B. (Amandine Barron), E.D. and P.A.; formal analysis, A.B. (Adrien Bosseboeuf), A.B. (Amandine Barron), E.D., A.G., P.S. and P.A.; investigation, A.B. (Adrien Bosseboeuf), A.B. (Amandine Barron) and E.D.; writing-original draft preparation, A.B. (Adrien Bosseboeuf); writing-review and editing, A.B. (Adrien Bosseboeuf), A.B. (Amandine Barron), E.D., A.G., P.S. and P.A.; supervision, A.B. (Amandine Barron), E.D., A.G., P.S. and P.A.; project administration and funding acquisition, P.S. and P. A.

Funding: This research was funded by the "Conseil Régional de Basse-Normandie" and "Fonds Européen de Développement Régional" (PEPTISAN project certified by the competitiveness cluster "Pole Mer Bretagne") and Kélia. Adrien Bosseboeuf PhD was supported by ANRT and Kelia (CIFRE grant).

Acknowledgments: Authors are grateful to Guillamin and Poulain of the Centre Francois Baclesse (Caen, France) for their help during flow cytometry experiments and analysis. We thank Goux. for checking the efficiency of the subcellular fractionation by electronic microscopy. The authors are grateful to Faliguerho and Lequenne of the 'Lycée Maritime et Aquacole de Cherbourg' (France) for capturing the dogfish specimens, the 'Citée de la Mer' (Cherbourg, France) and the 'Centre de Recherches en Environnement Côtier' (Luc-sur-mer, France) for the care given to the dogfish. Authors thank Joubel for the English proofreading.

Conflicts of Interest: The authors declare no conflict of interest.

\section{References}

1. Suarez-Jimenez, G.M.; Burgos-Hernandez, A.; Ezquerra-Brauer, J.M. Bioactive peptides and depsipeptides with anticancer potential: Sources from marine animals. Mar. Drugs 2012, 10, 963-986. [CrossRef] [PubMed]

2. Negi, B.; Kumar, D.; Rawat, D.S. Marine Peptides as Anticancer Agents: A Remedy to Mankind by Nature. Curr. Protein Pept. Sci. 2017, 18, 885-904. [CrossRef] [PubMed]

3. Lee, Y.; Phat, C.; Hong, S.C. Structural diversity of marine cyclic peptides and their molecular mechanisms for anticancer, antibacterial, antifungal, and other clinical applications. Peptides 2017, 95, 94-105. [CrossRef]

4. Blanco-Míguez, A.; Gutiérrez-Jácome, A.; Pérez-Pérez, M.; Pérez-Rodríguez, G.; Catalán-García, S.; Fdez-Riverola, F.; Lourenço, A.; Sánchez, B. From amino acid sequence to bioactivity: The biomedical potential of antitumor peptides. Protein Sci. 2016, 25, 1084-1095. [CrossRef]

5. Wang, L.; Dong, C.; Li, X.; Han, W.; Su, X. Anticancer potential of bioactive peptides from animal sources (Review). Oncol. Rep. 2017, 38, 637-651. [CrossRef]

6. Fan, M.; Nath, A.K.; Tang, Y.; Choi, Y.J.; Debnath, T.; Choi, E.J.; Kim, E.K. Investigation of the Anti-Prostate Cancer Properties of Marine-Derived Compounds. Mar. Drugs 2018, 16, 160-174. [CrossRef]

7. Huang, F.; Yang, Z.; Yu, D.; Wang, J.; Li, R.; Ding, G. Sepia ink oligopeptide induces apoptosis in prostate cancer cell lines via caspase-3 activation and elevation of Bax/Bcl-2 ratio. Mar. Drugs 2012, 10, 2153-2165. [CrossRef]

8. Huang, F.; Jing, Y.; Ding, G.; Yang, Z. Isolation and purification of novel peptides derived from Sepia ink: Effects on apoptosis of prostate cancer cell PC-3. Mol. Med. Rep. 2017, 16, 4222-4228. [CrossRef] 
9. Huang, F.; Ding, G.; Yang, Z.; Yu, F. Two novel peptides derived from Sinonovacula constricta inhibit the proliferation and induce apoptosis of human prostate cancer cells. Mol. Med. Rep. 2017, 16, 6697-6707. [CrossRef]

10. Yu, F.; Zhang, Y.; Ye, L.; Tang, Y.; Ding, G.; Zhang, X.; Yang, Z. A novel anti-proliferative pentapeptide (ILYMP) isolated from Cyclina sinensis protein hydrolysate induces apoptosis of DU-145 prostate cancer cells. Mol. Med. Rep. 2018, 18, 771-778. [CrossRef]

11. Bhargava, P.; Marshall, J.L.; Dahut, W.; Rizvi, N.; Trocky, N.; Williams, J.I.; Hait, H.; Song, S.; Holroyd, K.J.; Hawkins, M.J. A Phase I and Pharmacokinetic Study of Squalamine, a Novel Antiangiogenic Agent, in Patients with Advanced Cancers. Clin. Cancer Res. 2001, 7, 3912-3919.

12. Connolly, B.; Desai, A.; Garcia, C.A.; Thomas, E.; Gast, M.J. Squalamine lactate for exudative age-related macular degeneration. Ophthalmol. Clin. N. Am. 2006, 19, 381-391. [CrossRef]

13. Zasloff, M.; Adams, A.P.; Beckerman, B.; Campbell, A.; Han, Z.; Luijten, E.; Meza, I.; Julander, J.; Mishra, A.; $\mathrm{Qu}, \mathrm{W}$; et al. Squalamine as a broad-spectrum systemic antiviral agent with therapeutic potential. Proc. Natl. Acad. Sci. USA 2011, 108, 15978-15983. [CrossRef] [PubMed]

14. Márquez-Garbán, D.C.; Gorrín-Rivas, M.; Chen, H.W.; Sterling, C., Jr.; Elashoff, D.; Hamilton, N.; Pietras, R.J. Squalamine blocks tumor-associated angiogenesis and growth of human breast cancer cells with or without HER-2/neu overexpression. Cancer Lett. 2019, 449, 66-75. [CrossRef]

15. Lv, Z.; Ou, Y.; Li, Q.; Zhang, W.; Ye, B.; Wu, W. Expression, purification and bioactivities analysis of recombinant active peptide from shark liver. Mar. Drugs 2009, 7, 258-267. [CrossRef] [PubMed]

16. Nomura, A.; Noda, N.; Maruyama, S. Purification of angiotensin I-converting enzyme inhibitors in pelagic thresher Alopias pelagicus muscle hydrolysate and viscera extracts. Fish Sci. 2002, 68, 954-956. [CrossRef]

17. García-Moreno, P.J.; Espejo-Carpio, F.J.; Guadix, A.; Guadix, E.M. Production and identification of angiotensin I-converting enzyme (ACE) inhibitory peptides from Mediterranean fish discards. J. Funct. Foods 2015, 18, 95-105. [CrossRef]

18. Ngo, D.-H.; Kang, K.-H.; Ryu, B.; Vo, T.-S.; Jung, W.-K.; Byun, H.-G.; Kim, S.-K. Angiotensin-I converting enzyme inhibitory peptides from antihypertensive skate (Okamejei kenojei) skin gelatin hydrolysate in spontaneously hypertensive rats. Food Chem. 2015, 174, 37-43. [CrossRef]

19. Zheng, L.; Ling, P.; Wang, Z.; Niu, R.; Hu, C.; Zhang, T.; Lin, X. A novel polypeptide from shark cartilage with potent anti-angiogenic activity. Cancer Biol. Ther. 2007, 6, 775-780. [CrossRef]

20. Pan, X.; Zhao, Y.Q.; Hu, F.Y.; Chi, C.F.; Wang, B. Anticancer Activity of a Hexapeptide from Skate (Raja porosa) Cartilage Protein Hydrolysate in HeLa Cells. Mar. Drugs 2016, 14, 153. [CrossRef]

21. Auvray, P.; Duval, E. Peptides isolés et purifiés à partir de testicules de roussettes. WO 2012/130999 A1 4 October 2012.

22. White, E.J.; Martin, V.; Liu, J.-L.; Klein, S.R.; Piya, S.; Gomez-Manzano, C.; Fueyo, J.; Jiang, H. Autophagy regulation in cancer development and therapy. Am. J. Cancer Res. 2011, 1, 362-372. [PubMed]

23. Esteve, J.M.; Knecht, E. Mechanisms of autophagy and apoptosis: Recent developments in breast cancer cells. World J. Biol. Chem. 2011, 2, 232-238. [CrossRef] [PubMed]

24. Su, Z.; Yang, Z.; Xu, Y.; Chen, Y.; Yu, Q. Apoptosis, autophagy, necroptosis, and cancer metastasis. Mol. Cancer 2015, 14, 48. [CrossRef] [PubMed]

25. Kundu, S.; Kim, T.H.; Yoon, J.H.; Shin, H.S.; Lee, J.; Jung, J.H.; Kim, H.S. Viriditoxin regulates apoptosis and autophagy via mitotic catastrophe and microtubule formation in human prostate cancer cells. Int. J. Oncol. 2014, 45, 2331-2340. [CrossRef] [PubMed]

26. Liu, Y.; Wang, M.; Wang, D.; Li, X.; Wang, W.; Lou, H.; Yuan, H. Malformin A1 promotes cell death through induction of apoptosis, necrosis and autophagy in prostate cancer cells. Cancer Chemother. Pharmacol. 2016, 77, 63-75. [CrossRef] [PubMed]

27. Amaravadi, R.K.; Yu, D.; Lum, J.J.; Bui, T.; Christophorou, M.A.; Evan, G.I.; Thomas-tikhonenko, A.; Thompson, C.B. Autophagy inhibition enhances therapy-induced apoptosis in a Myc-induced model of lymphoma. J. Clin. Investig. 2007, 117, 326-336. [CrossRef]

28. Racoma, I.O.; Meisen, W.H.; Wang, Q.-E.; Kaur, B.; Wani, A.A. Thymoquinone inhibits autophagy and induces cathepsin-mediated, caspase-independent cell death in glioblastoma cells. PLoS ONE 2013, 8, e72882. [CrossRef]

29. Kast, D.J.; Dominguez, R. The Cytoskeleton-Autophagy Connection. Curr. Biol. 2017, 27, R318-R326. [CrossRef] 
30. Wills, J.; Credle, J.; Oaks, A.W.; Duka, V.; Lee, J.-H.; Jones, J.; Sidhu, A. Paraquat, but not maneb, induces synucleinopathy and tauopathy in striata of mice through inhibition of proteasomal and autophagic pathways. PLOS ONE 2012, 7, e30745. [CrossRef]

31. di Pietro, F.; Echard, A.; Morin, X. Regulation of mitotic spindle orientation: An integrated view. EMBO Rep. 2016, 17, 1106-1130. [CrossRef]

32. Jackson, S.J.T.; Singletary, K.W. Sulforaphane: A naturally occurring mammary carcinoma mitotic inhibitor, which disrupts tubulin polymerization. Carcinogenesis 2004, 25, 219-227. [CrossRef] [PubMed]

33. Appierto, V.; Tiberio, P.; Cavadini, E.; Casalini, P.; Cappelletti, G.; Formelli, F. Antimitotic effect of the retinoid 4-oxo-fenretinide through inhibition of tubulin polymerization: A novel mechanism of retinoid growth-inhibitory activity. Mol. Cancer Ther. 2009, 8, 3360-3368. [CrossRef] [PubMed]

34. Duangmano, S.; Sae-Lim, P.; Suksamrarn, A.; Domann, F.E.; Patmasiriwat, P. Cucurbitacin B inhibits human breast cancer cell proliferation through disruption of microtubule polymerization and nucleophosmin/B23 translocation. BMC Complement. Altern. Med. 2012, 12, 185. [CrossRef]

35. Park, C.J.; Song, S.; Lee, P.R.; Shou, W.; Deshaies, R.J.; Lee, K.S. Loss of CDC5 Function in Saccharomyces cerevisiae Leads to Defects in Swe1p Regulation and Bfa1p/Bub2p-Independent Cytokinesis. Genetics 2003, 33, 21-33.

36. Dayma, K.; Radha, V. Cytoskeletal remodeling by C3G to induce neurite-like extensions and inhibit motility in highly invasive breast carcinoma cells. Biochim. Biophys. Acta 2011, 1813, 456-465. [CrossRef]

37. Strobl, J.S.; Nikkhah, M.; Agah, M. Actions of the anti-cancer drug suberoylanilide hydroxamic acid (SAHA) on human breast cancer cytoarchitecture in silicon microstructures. Biomaterials 2010, 31, 7043-7050. [CrossRef]

(C) 2019 by the authors. Licensee MDPI, Basel, Switzerland. This article is an open access article distributed under the terms and conditions of the Creative Commons Attribution (CC BY) license (http://creativecommons.org/licenses/by/4.0/). 